\title{
MODERNIZAÇÃO DA AGRICULTURA E USO DO TERRITÓRIO: A DIALÉTICA ENTRE O NOVO E O VELHO, O INTERNO E O EXTERNO, O MERCADO E O ESTADO EM ÁREAS DE CERRADO*
}

\author{
Samuel Frederico
}

Resumo: O artigo analisa a expansão e a consolidação da fronteira agrícola moderna em áreas de cerrado. Na segunda metade do século $X X$, a agricultura brasileira passou por dois períodos de modernização: o primeiro, na década de 1970, caracterizado pela internalização do paradigma da Revolução Verde, pela formação dos complexos agroindustriais e pela forte regulação estatal; e o segundo, na década de 1990, com a emergência da agricultura científica globalizada, caracterizada pelo uso das novas tecnologias da informação e pelo maior poder de regulação das grandes empresas. Os novos paradigmas produtivos agrícolas não só alteraram as relações entre o campo e a cidade, mas, sobretudo, entre os lugares e regiões da produção agrícola moderna e o mundo, submetendo os primeiros a uma lógica única, que não podem prever e nem mesmo controlar.

Palavras-chave: Fronteira agrícola moderna; cerrado; agricultura científica globalizada; regiões competitivas agrícolas; cidades do agronegócio.

\section{MODERNIZATION OF AGRICULTURE AND USE OF TERRITORY: THE DIALETIC BETWEEN NEW AND OLD, INTERNAL AND EXTERNAL, MARKET AND STATE IN AREAS OD CERRADO}

\begin{abstract}
This article analyzes the expansion and consolidation of the modern agricultural frontier in the cerrado. In the second half of the XX century, Brazilian agriculture has had two periods of modernization: the first, in the 1970s, characterized by the Green Revolution paradigm, the formation of the agroindustrial complex and State regulation; and the second, in the 1990s, characterized by the emergence of globalized scientific agricultural, i.e. the use of new information technologies and the regulation of the crops produced by big companies. The new paradigms of agriculture have changed the relationship between the country and the city and especially that between the agricultural regions and the world economy.
\end{abstract}

Keywords: Modern agricultural frontier; cerrado; globalized scientific agriculture; competitive agricultural regions; agribusiness cities.

\section{Introdução}

O artigo se propõe a analisar como a expansão da fronteira agrícola moderna em áreas de cerrado ampliou as contradições entre três dos principais pares dialéticos que, segundo Santos (1985, p. 75), configuram a "evolução espacial": o "novo e o velho", "o interno e o externo", "o mercado e o Estado". Trata-se de compreender como o "campo de forças" estabelecido entre os arranjos espaciais pretéritos e as novas ações e objetos, a organização interna confrontada com os eventos externos, e a regulação do
Estado e o poder das empresas, transformaram, nas últimas quatro décadas, a configuração territorial e o uso do território do cerrado.

Os pares dialéticos supracitados não esgotam a gama quase infinita de oposições existentes na dinâmica espacial, mas possibilitam analisar três das suas principais contradições: a) a cooperação e o conflito entre os principais agentes que atuam na fronteira agrícola moderna (empresas,

\footnotetext{
* Este artigo deriva da tese de doutorado o novo tempo do cerrado: expansão dos fronts agrícolas e controle do sistema de armazenamento de grãos", orientada pelo Prof. Dr. Francisco Capuano Scarlato e defendida no Programa de Pós-Graduação em Geografia Humana da Faculdade de Filosofia Letras e Ciências Humanas da Universidade de São Paulo, no ano de 2009.
} 
produtores e o Estado); b) a relação entre o trabalho morto (rodovias, silos, ferrovias, estrutura fundiária, infraestruturas urbanas) e o trabalho vivo (ação); c) e o papel dos eventos externos à região e/ou à formação socioespacial (SANTOS, 1977) que se implantam nos lugares e entram em contradição com normas e técnicas preexistentes.

O principal evento que integrou 0 "Grande Cerrado do Brasil Central" (DINIZ, 2006) ao tempo do mundo (SANTOS, 1996) foi a ampliação da fronteira agrícola moderna. Trata-se da expansão e consolidação da agricultura moderna intensiva em capital e tecnologia, poupadora de mão de obra, realizada em grandes propriedades monocultoras e destinada, principalmente, à exportação -, em áreas de cerrado.

Num primeiro momento (década de 1970), o Estado foi o principal articulador e financiador da expansão da fronteira agrícola moderna, por meio de incentivos fiscais e creditícios, da construção de infraestruturas de transporte e armazenamento e da criação de políticas de colonização e modernização da agricultura. A partir da década de 1990, com a adoção das políticas neoliberais, ele cede lugar à maior atuação política das grandes empresas transnacionais do comércio de grãos, agroindustriais e de insumos agrícolas.

Não que o Estado se torne ausente, ele continua presente, sobretudo, no financiamento da construção de macrossistemas de engenharia necessários à circulação dos grãos. No entanto, as grandes empresas tornaram-se proeminentes no financiamento agrícola e no controle da logística.
Além de atrair novos agentes, a difusão da agricultura moderna também alterou a relação entre o campo e a cidade. $\mathrm{O}$ aprofundamento da especialização de ambas as dimensões territoriais ampliou o seu intercâmbio. Diversas cidades da fronteira agrícola tornaram-se funcionais ao campo moderno (SANTOS, 1993), concentrando comércios e serviços necessários à produção agrícola. Pode-se afirmar, que nas regiões agrícolas modernas a antiga relação campocidade, na qual o primeiro abastecia o segundo, se altera, agora são as cidades que se especializam para fornecer os insumos necessários ao campo modernizado.

As contradições e os conflitos decorrentes da "arena de forças" estabelecida pela relação entre o novo e o velho, o interno e o externo, o mercado e o Estado são inseparáveis. O Estado, às vezes, é o portador do externo e do novo, mas dependendo do arranjo político também garante a permanência do velho e do interno. As empresas, na maioria das vezes, são as responsáveis pela introdução do externo e do novo, devido à sua ação reticular, mas ao chegar aos lugares, elas recriam o interno e também são responsáveis pelo velho.

Inúmeros eventos nos permitem construir um concreto pensado (SILVEIRA, 2000) resultante da relação entre os pares dialéticos anteriores. Dentre as possibilidades, o artigo se propõe a analisar três eventos significativos: a expansão da agricultura moderna em áreas de cerrado e o conflito entre o novo e o velho; a constituição de regiões e cidades funcionais ao campo moderno, decorrente da relação entre o externo e o interno; e a relação de conflito e cooperação entre o Estado e as empresas exportadoras de grãos. 
O novo e o velho: agricultura científica globalizada e expansão da fronteira agrícola moderna

Parcela significativa da agricultura brasileira sofreu profundas transformações nas últimas décadas do século $X X$. A uma agricultura de base local, com circuitos produtivos (SANTOS, 1986) circunscritos regionalmente, se sobrepôs uma agricultura moderna, cada vez mais mundializada, cuja lógica de funcionamento transcende os lugares e até mesmo as fronteiras do território nacional. Desde a década de 1970, o campo brasileiro conheceu ao menos duas vagas de modernização: a primeira pautada na formação dos complexos agroindustriais (CAIs), na internalização do paradigma da Revolução Verde (PORTO-GONÇALVES, 2006) e na centralidade do Estado; e a segunda, que a partir da década de 1990, substituiu gradativamente a primeira, caracterizada pela emergência da agricultura científica globalizada (SANTOS, 2000).

O primeiro momento marcou a reformulação da base técnica e político/normativa da agricultura brasileira, com a internalização do paradigma da Revolução Verde e com a formação dos complexos agroindustriais (CAIs). Aquele paradigma se caracterizou pelo desenvolvimento - pelo ao menos para alguns produtores, culturas e regiões - de cultivares mais produtivos, sensíveis ao uso de insumos químicos, mecânicos e irrigação. A formação dos complexos agroindustriais, grosso modo, decorreu da modernização agrícola e da integração entre a agricultura e a indústria, tanto a montante quanto a jusante da propriedade agrícola, assim como, com os ramos da distribuição e comércio. ${ }^{1}$

O Estado foi o principal financiador e articulador dos agentes responsáveis pela modernização do campo e pela formação dos complexos agroindustriais. Dentre as principais políticas destacam-se: o fornecimento de crédito subsidiado para custeio e investimento, atrelado à adoção da nova base técnica; a internalização da indústria a montante, produtora de bens de capital; as articulações entre as empresas públicas de pesquisa - responsáveis pelo desenvolvimento dos novos cultivares - e as multinacionais produtoras de insumos químicos e mecânicos; o incentivo fiscal e creditício às agroindústrias; a extensão rural, difundindo as novas técnicas de manejo; a criação de uma rede de armazéns públicos e os investimentos em transporte e energia.

Como bem demonstra Graziano da Silva (1980), a modernização da agricultura brasileira solucionou a "questão agrícola", ao promover um aumento exponencial da produtividade e da área plantada de grãos, mas aprofundou a "questão agrária", ao concentrar as terras e expulsar do campo parcela significativa de produtores campesinos. Os principais beneficiados pela modernização do campo foram os grandes produtores agrícolas, grandes agroindústrias e empresas multinacionais fabricantes de agrotóxicos, maquinário agrícola e do comércio mundial de grãos.

Na última década do século $X X$, com a inserção definitiva da formação

\footnotetext{
1 Existem variações com relação à definição do conceito de complexo agroindustrial. Para uma análise mais detalhada, consultar Sorj (1980), Silva (1982), Delgado (1985), Müller (1986), Kageyama (1990), Mazzali (2000).
} 
socioespacial brasileira no atual período da globalização (SANTOS, 2000), transformações de ordem técnica e político-normativa alteraram novamente o padrão de organização de parcela do campo brasileiro. Dentre as alterações de ordem normativa destaca-se a adoção das políticas neoliberais (HARVEY, 2007), permitindo a grandes empresas agroindustriais e tradings transnacionais - articuladas em rede entre si, com empresas complementares e com o Estado (MAZZALI, 2000) -, exercer gradativamente as antigas funções estatais como o fornecimento de crédito de custeio, a inovação tecnológica e o armazenamento e transporte dos grãos.

Com relação às mudanças de ordem técnica sobressai a emergência das novas tecnologias da informação e da comunicação (NTIC), que aperfeiçoou e/ou substituiu os sistemas técnicos provenientes do paradigma da Revolução Verde (agrotóxicos, mecanização, irrigação, sementes selecionadas). A nova vaga de modernização introduziu no campo o uso da informática, da microeletrônica, da biotecnologia, da engenharia genética, da agricultura de precisão e da formação e transmissão de bancos de dados, resultando numa crescente demanda externa de racionalidade.

O uso intensivo de bens científicos, a padronização dos procedimentos (preparação do terreno, plantio, tratos culturais, colheita, armazenamento, transporte, beneficiamento e comercialização) e a dependência do crédito privado tornaram os produtores e os próprios lugares obedientes, segundo Santos (2000, p. 90), a fatores externos, que "não podem prever e nem mesmo controlar". Para Castillo (2008), a crescente exigência de ciência, tecnologia, informação e capital para a maior eficiência produtiva tem resultado numa divisão territorial do trabalho caracterizada pelo controle técnico local e por um controle político (regulação) distante da produção.

Nos lugares e regiões da produção propriamente dita, a grande racionalidade técnica das ações tem resultado na redução dos custos de produção, no aumento da produtividade, numa logística mais eficiente e na superexploração da força de trabalho e dos recursos naturais, inserindo-os de forma competitiva no mercado globalizado. Contudo, o controle político da produção não se realiza localmente. As ordens das grandes empresas, instituições, especuladores financeiros e Estados - que designam direta ou indiretamente a forma de produzir (técnicas de manejo), de armazenar, de transportar, a disponibilidade e o custo do dinheiro, o câmbio, os lucros dos intermediários, os preços, os prazos e as quantidades adquiridas -, provêm dos grandes centros decisórios, internos e externos à formação socioespacial brasileira.

A emergência de uma agricultura científica globalizada tornou o "mundo" um parceiro inconstante e pouco confiável dos produtores (CASTILLO; FREDERICO, 2010a), que se defrontam, segundo Santos (2000), com um mercado longínquo, de certa maneira abstrato, com uma concorrência invisível e com preços internacionais sobre os quais não há nenhum controle local.

A maior densidade técnica e informacional da produção agrícola tem resultado num acelerado crescimento da área e redução da arena de produção (SANTOS, 1996), isto é, o maior distanciamento das diferentes etapas dos circuitos espaciais 
produtivos (produção propriamente dita, distribuição, troca e consumo) e o aumento vertiginoso da produtividade. Os diferentes lugares da produção agrícola moderna estão cada vez mais submetidos a uma divisão territorial e internacional do trabalho, cujas decisões político-normativas não possuem nenhum controle, enquanto se especializam e produzem grãos com grande eficiência e com baixo custo relativo.

Dentre as áreas do território brasileiro, o cerrado é onde a agricultura científica globalizada tem se consolidado e expandido com maior velocidade e eficiência. Dentre os principais fatores dessa expansão destacam-se: a disponibilidade de fundos territoriais $^{2}$ (MORAES, 2000), isto é, áreas de reserva passíveis de serem ocupadas, reconvertidas e valorizadas pela produção agrícola moderna; a presença de menores rugosidades, ou seja, poucas heranças sociopolíticas e técnico-territoriais (SANTOS, 1996); e o desenvolvimento de sistemas técnicos agrícolas adaptados às condições edafoclimáticas do cerrado.

Nesta grande área do Brasil Central, o crescimento exponencial da produtividade agrícola, principalmente, de soja, algodão e milho, ocorre paralelamente à ocupação de novas áreas, em substituição à cobertura vegetal original, ${ }^{3}$ às áreas de pastagens e à produção campesina.

\footnotetext{
2 Segundo dados da Embrapa (2002), o Cerrado possui uma área de 204 milhões de hectares, sendo que destes, 61 milhões eram utilizados para agricultura, em 2002. A empresa estatal projeta uma capacidade adicional de uso de 66 milhões, uma vez que os restantes 77 milhões de hectares são considerados impróprios para a prática agrícola.

${ }^{3}$ Segundo dados do Ministério do Meio Ambiente, entre 2002 e 2008, um terço do desmatamento do bioma Cerrado se concentrou em 60 municípios, todos localizados nas principais regiões de
}

O cerrado é conhecido também como o "polígono dos solos ácidos" ou "planaltos tropicais interiorizados", que corresponde, segundo Ab'Saber (2003, p. 117), a um dos "grandes polígonos irregulares que formam o mosaico paisagísticos brasileiro". Com uma área de pouco mais de 2 milhões $\mathrm{km}^{2}$ (MMA/IBGE), equivalente a 1/4 da extensão territorial brasileira, o cerrado possui condições topográficas (planalto, com grandes áreas planas e solos profundos) e climáticas (duas estações do ano bem definidas, uma chuvosa e outra seca, e intensa luminosidade) favoráveis à agricultura moderna.

Mapa 1 - Área original do bioma cerrado

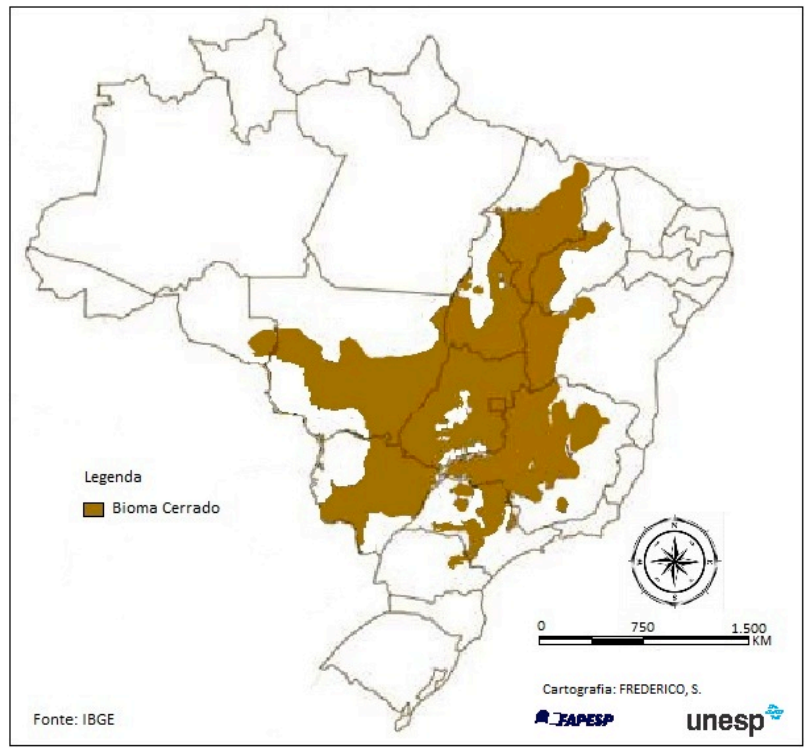

Como relatado anteriormente, a partir da década de 1970, o Estado foi o principal promotor da expansão da fronteira agrícola moderna com os objetivos de aumentar a produção de grãos - com vistas a acrescer as exportações e a suprir a demanda de um país que se urbanizava e se industrializava -, e de garantir a integridade do território nacional, ocupando as áreas fronteiriças e transferindo

expansão da fronteira agrícola como Oeste da Bahia, Sul do Maranhão, Chapada dos Parecis (MT) e Centro-Norte do Mato Grosso. 
a população das áreas mais densamente povoadas e de maiores conflitos fundiários.

O recuo dos fundos territoriais e a implantação de uma agricultura moderna no cerrado promoveu uma "acumulação por espoliação" (HARVEY, 2004), isto é, criou novas formas de ampliação do capital, principalmente, para grandes produtores e empresas multinacionais.

A partir da década de 1990, a forte atuação estatal vai cedendo espaço a uma maior atuação política das grandes empresas agrícolas. Estas passaram a atuar principalmente em atividades estratégicas, como o processamento agroindustrial e o controle da circulação material (armazenamento, beneficiamento, transporte, venda de sementes e fertilizantes) e imaterial (financiamento, comercialização, exportação, capitais). A participação do Estado continua importante e requisitada em algumas áreas mais onerosas e menos interessantes para as empresas privadas, como o financiamento e a construção de infraestruturas (ferrovias, hidrovias, portos), o fornecimento de parte do crédito de investimento e custeio e o desenvolvimento de novos cultivares agrícolas.

\section{Interno e externo: regiões competitivas agrícolas e as cidades do agronegócio}

A modernização e a expansão da produção agrícola no território brasileiro têm levado à constituição de regiões competitivas (CASTILLO, 2008) e cidades funcionais ao campo (SANTOS, 1993; ELIAS, 2007). A emergência de regiões competitivas agrícolas deriva da especialização de porções do território brasileiro na produção de commodities de exportação. Nessas regiões, não é apenas o campo que sofre profundas alterações, mas as cidades também se reorganizam para atender às exigências da produção agrícola dominante. Pode-se dizer que a velha relação campo-cidade se altera, porque, muitas vezes, não é mais o campo que abastece com gêneros alimentícios a cidade próxima, mas são as cidades que passam a suprir as demandas produtivas do campo modernizado.

As regiões agrícolas modernas são o resultado único da combinação dos aconteceres homólogo, complementar e hierárquico (SANTOS, 1996). Estas três formas do acontecer solidário permitem analisar como a ingerência de eventos externos, portadores de uma racionalidade dominante, reorganizam o campo e as cidades, assim como o intercâmbio estabelecido entre essas dimensões territoriais.

Os "aconteceres solidários" são expressões da atual divisão territorial e internacional do trabalho, que por intermédio dos eventos em rede estabelecem a ligação entre os lugares e o mundo. Para Santos (1996), enquanto os aconteceres homólogo e complementar definem-se pela proximidade, pela "contiguidade espacial" e pela "copresença" dos agentes, o acontecer hierárquico distingue-se pela "proximidade organizacional", pela "relação pontual" operada em rede.

Como propõe Santos (1985, p. 77), a "evolução do espaço" supõe um embate entre forças "externas" e "internas", ou seja, a existência de um acontecer hierárquico que de forma contraditória redefine, a cada 
momento, os demais aconteceres solidários pautados pelo cotidiano e pela contiguidade.

O acontecer hierárquico define-se pela cisão, ainda que metafórica, entre "espaços do mandar" e "espaços do fazer" (SANTOS; SILVEIRA, 2001), isto é, ordens e informações produzidas num dado lugar e realizadas em outro. O acontecer homólogo é aquele próprio das áreas urbanas ou agrícolas, que se modernizam para atender ao nexo produtivo dominante. E por fim, o acontecer complementar se expressa pelas relações estabelecidas entre as próprias cidades e destas com o campo.

As regiões competitivas agrícolas provêm do acontecer hierárquico, isto é, da integração reticular de determinadas áreas do território aos mercados internacionais. A modernização e a difusão das redes, ao mesmo tempo em que elimina a antiga noção de região, pautada na duração de seus limites, recria um novo tipo, funcional aos mercados internacionais. Como ressalva Milton Santos (1985; 1996), a região não têm existência em si mesma, ela define-se como um compartimento produtivo do espaço geográfico atrelado às exigências da divisão internacional e territorial do trabalho.

$\mathrm{Na}$ fronteira agrícola moderna, as especializações produtivas regionais decorrem da submissão de parcelas do território à lógica mundial das commodities. ${ }^{4}$

\footnotetext{
4 Numa perspectiva geográfica, a lógica das commodities não se caracteriza apenas por uma invenção econômico-financeira, definida pela padronização dos preços e da qualidade dos produtos primários e semielaborados. Trata-se também de uma expressão territorial, que resulta na exacerbação de especializações regionais produtivas enfraquecendo e submetendo 0 produtor local a uma lógica externa e a uma situação sobre a qual não exerce nenhum controle, favorecendo os compradores ou as grandes empresas de comercialização (tradings). A lógica
}

O exponencial aumento da produção de grãos no cerrado está vinculado diretamente ao "imperativo das exportações" (SANTOS, 1999). Trata-se da adoção pelo Estado brasileiro da lógica ricardiana das "vantagens comparativas" (REINERT, 2007), que resulta na especialização de parcela significativa de seu território na produção de commodities agrícolas, para atender, em última instância, ao nexo financeiro da economia. ${ }^{5}$

No território brasileiro, dos 65,5 milhões de hectares cultivados com gêneros agrícolas, no ano de 2009, aproximadamente $35 \%$ foram cultivados exclusivamente com soja (principal commodity agrícola brasileira). O percentual da área plantada de soja aumenta para $59,7 \%$ do total, quando consideramos apenas a região Centro-Oeste, para $66,1 \%$ no caso do estado do Mato Grosso e se aproxima dos 80\% em diversas regiões desse estado, como o Meio-Norte e o Sudeste. $^{6}$

A fronteira agrícola moderna produz $60 \%$ da soja nacional, contendo os 34 maiores municípios produtores. Somente o estado do Mato Grosso produz cerca de $30 \%$ do total nacional, possuindo oito municípios entre os dez maiores produtores. ${ }^{7}$

das commodities opõe agentes atrelados ao lugar ou região aos agentes que atuam em rede na escala mundial, acarretando numa vulnerabilidade social, econômica e territorial.

5 As políticas estatais de incremento das exportações, vigentes pelo ao menos desde a década de 1990, têm como principal objetivo a realização do superávit primário, com o intuito de atender ao pagamento dos juros dos títulos da dívida pública, remunerando, assim, sobretudo, os grandes investidores e especuladores do mercado financeiro internacional.

${ }^{6}$ Dados da Produção Agrícola Municipal fornecidos pelo Instituto Brasileiro de Geografia e Estatística, ano 2009.

7 Idem. 
Mapa 2 - Área plantada de soja na fronteira agrícola moderna, 2009

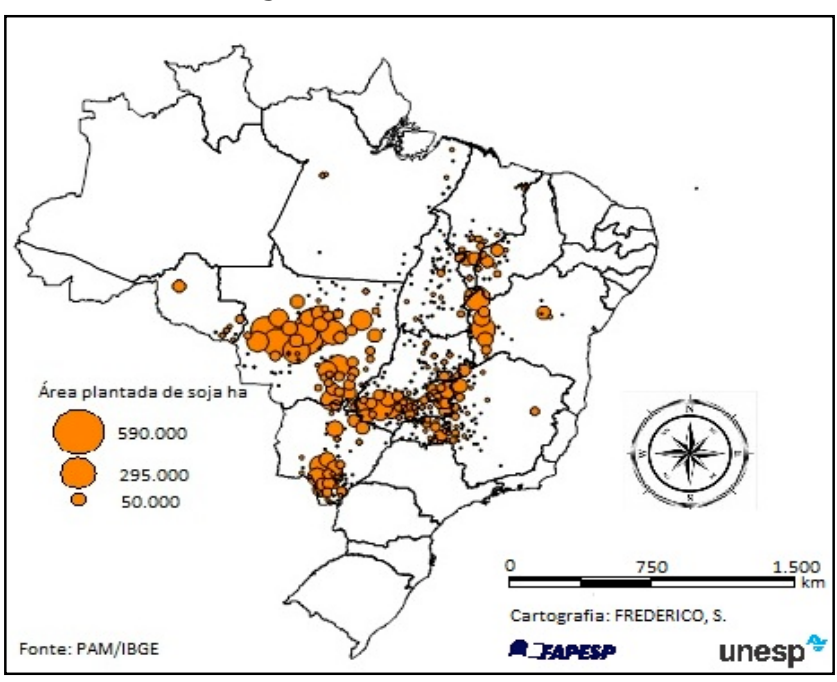

A área plantada de soja continua a se expandir em diversas regiões da fronteira agrícola moderna: no estado do Maranhão, as plantações têm se expandido na região de Chapadinha, no nordeste do estado, e do sul (município de Balsas) em direção à área central e leste; no Piauí, a área cultivada continua a se expandir na região sudoeste (Gurgueia); na Bahia, o crescimento da área continua a ocorrer no extremo oeste, partindo dos municípios de Barreiras e Luís Eduardo Magalhães em direção aos municípios de Formosa do Rio Preto (sentido norte) e Cocos (sentido sul); em Rondônia, a soja tem se expandido na porção leste, a partir da divisa com o estado do Mato Grosso; neste, a expansão tem ocorrido nas áreas próximas à referida divisa, ao longo da BR-158 (no leste-nordeste do estado), na área de influência da BR-163 e nos municípios localizados ao norte e ao sul do Parque Indígena do Xingu; em Goiás, a área plantada tem se expandido no entorno do Distrito Federal, seguindo em direção nordeste (Chapada dos Veadeiros e município de Flores de Goiás); no Pará, a soja tem se expandido na região nordeste do estado, a partir da divisa com o Maranhão (ao longo da
BR-010); em Minas Gerais, a soja concentrase principalmente no noroeste do estado, próximo à divisa com Goiás, e na região do Triângulo Mineiro; por fim, a área plantada de soja também teve um aumento significativo em diferentes pontos dos estados de Tocantins e do Mato Grosso do Sul.

Como demonstrado por diversos autores, dentre eles, Bernardes; (2009; 2010), Castillo (2005; 2011), Frederico (2010), Huertas (2009), Vencovscky (2011), as regiões de fronteira agrícola, especializadas na produção moderna de soja, atraem investimentos públicos e privados (crédito de custeio e investimento, novas tecnologias produtivas, logística) e reúnem uma série de fatores produtivos (conhecimento, serviços, maquinário, insumos modernos, infraestruturas de transporte, armazenagem e comunicação), que Ihes conferem uma maior eficiência produtiva e uma integração competitiva nos mercados internacionais.

A especialização regional em commodities agrícolas ao mesmo tempo em que torna o território moderno e competitivo no mercado internacional, também induz à sua fragmentação e desintegração. A fragmentação diz respeito ao predomínio de vínculos externos, em detrimento de relações com os espaços adjacentes, criando um cotidiano obediente a parâmetros externos da economia e da política. A desintegração decorre da relação desigual e do privilégio conferido a determinadas regiões pelos investimentos públicos e privados, provocando o que Araújo (2000) denominou de "desintegração competitiva". Ao atrair investimentos para se inserirem de forma competitiva nos mercados internacionais, 
essas regiões acabam por "fragmentar" o seu entorno e "desintegrar" o restante do território, configurando-se como "ilhas de eficiência produtiva".

\section{As cidades do agronegócio}

Dentre os principais signos da expansão e consolidação da fronteira agrícola moderna destaca-se a reestruturação do acontecer homólogo e complementar, isto é, a modernização e a especialização do campo e das cidades e o aumento do intercâmbio de informação, capital e dinheiro, entre essas dimensões territoriais.

Os núcleos urbanos surgidos ou adaptados à demanda do campo moderno são denominados, por Elias (2007, p. 120), de "cidades do agronegócio". Estas, segundo a autora, são aquelas "cujas funções de atendimento às demandas do agronegócio globalizado são hegemônicas sobre as demais funções".

Com a modernização do campo, a cidade tornou-se o centro da regulação da produção, nela ocorrem o consumo dos serviços e o tratamento e retransmissão das informações oriundas de diversas partes do globo. De acordo com Santos (1993), as cidades do agronegócio atendem ao consumo produtivo e consumptivo (familiar). A primeira forma está vinculada ao consumo dos serviços e bens materiais para atender ao nexo produtivo (consultorias agronômica e financeira, mão de obra com ou sem especialização, insumos químicos, mecânicos e biológicos, pesquisas científicas, transporte e armazenamento). O consumo familiar complementa o primeiro e relaciona-se às demandas da população (serviços diversos, bens de consumo duráveis e não duráveis).

Nas cidades do agronegócio, a
hierarquia urbana é redefinida pela
quantidade e qualidade dos serviços e
comércios existentes para atender aos
consumos produtivos e consumptivos.
Algumas cidades tornam-se novos centros regionais enquanto outras perdem a posição exercida em períodos anteriores. A reestruturação da hierarquia é acompanhada de uma maior especialização dos núcleos urbanos, aprofundando a divisão territorial do trabalho e acarretando na necessidade da criação de mais fluxos.

Cria-se, assim, de acordo com Santos (1993), um círculo "vicioso" entre especialização do território e aumento da circulação. Esse fenômeno promove uma maior inter-relação entre o local e o global, devido à necessidade de intensificação dos fluxos materiais e imateriais, conectando centros locais e regionais diretamente com as metrópoles nacionais e mundiais.

No caso da fronteira agrícola moderna torna-se evidente a centralidade exercida pela cidade de São Paulo. A difusão das redes geográficas permitiu a separação entre os espaços "produtores de massa" e os "espaços produtores de fluxo", como propõem Santos e Silveira (2001). Enquanto a arena de produção de soja expande-se por quase todo o território nacional, o comando da produção resta concentrado, sobretudo, na capital paulista.

Esta, mesmo sem produzir um grão de soja, é a maior exportadora brasileira da oleaginosa, movimentando quase um terço 
do total produzido. ${ }^{8}$ A capacidade decorre da presença na cidade dos escritórios das principais empresas exportadoras de commodities agrícolas (Cargill, Bunge, Louis Dreyfus, Multigrain e Agrenco). Além dos escritórios comerciais, Cataia (2005) ressalta que a cidade de São Paulo também centraliza outros serviços altamente especializados e necessários para a realização da produção agrícola moderna, como: consultorias jurídicas, financeiras e comerciais, Bolsas de Valores, associações de classe e escritórios centrais de empresas agroindustriais, de logística, de maquinário e de insumos agrícolas.

A concentração dos serviços de alta especialização relacionados ao terciário superior torna a cidade de São Paulo onipresente em toda a fronteira agrícola, produzindo e comandando parte dos fluxos financeiros, informacionais e de mercadorias. Isso não quer dizer que São Paulo comande todo o agronegócio (altamente dominado e incentivado pelos governos estaduais, pelas multinacionais e pelos produtores), mas que possui uma atuação significativa numa etapa importante da produção que é a exportação dos grãos e a assessoria jurídica e financeira.

Nas regiões agrícolas, algumas cidades se destacam como importantes centros regionais, como: Rondonópolis (MT), Rio Verde (GO), Balsas (MA), Barreiras (BA) e Dourados (MS). Elas estabelecem ao mesmo tempo relações diretas com a metrópole nacional de São Paulo e com centros importadores e financeiros internacionais. Para Bernardes (2010, p. 2021), "a criação das redes de produção

\footnotetext{
8 Dados da Secretaria do Comércio Exterior do Ministério do Desenvolvimento, Indústria e Comércio, ano de 2007.
}

agropecuárias globalizadas explica em parte as novas relações campo/cidade, a organização de sistemas urbanos mais complexos e as inter-relações cada vez mais intensas entre as cidades".

Nas cidades do "Brasil agrícola" (SANTOS, 1993), a organização territorial urbana tornou-se funcional ao campo moderno, concentrando os fixos (armazéns, escritórios exportadores, bancos, aeroportos, terminais de transporte, sistemas de energia e comunicação) necessários à realização dos fluxos inerentes aos circuitos espaciais produtivos e aos círculos de cooperação agrícola (CASTILLO; FREDERICO, 2010b).

A emergência de novos sistemas produtivos agrícolas, pautados, sobretudo, na biotecnologia, na microeletrônica e nas tecnologias da informação, e a mundialização dos circuitos espaciais produtivos promoveram transformações quantitativas e qualitativas nos fluxos entre o campo e a cidade e destas com o mundo.

Dentre os serviços ofertados pelas cidades ao campo moderno sobressaem-se: a revenda de insumos químicos, mecânicos e biológicos; a prestação de consultorias agronômicas, logística, financeira e de mercado; o beneficiamento e processamento agroindustrial dos grãos; o armazenamento e o transporte de insumos e produtos agrícolas; o fornecimento do crédito de investimento e custeio (via bancos e empresas privadas); e a comercialização dos grãos (via corretores e tradings).

$$
\text { Contudo, a modernização }
$$

"excludente" do campo, ao mesmo tempo em que promove o crescimento e a importância das cidades, aprofunda a desigualdade de acesso às infraestruturas sociais urbanas. A 
concentração fundiária, o uso intensivo de maquinário e a produção monocultora destinada, sobretudo, à exportação, excluem do campo os pequenos produtores de base familiar, a mão de obra assalariada e outras formas possíveis de produção. Os excluídos do campo buscam abrigo nas cidades, que ao se tornarem "espaços luminosos" (SANTOS; SILVEIRA, 2001), pela concentração de infraestruturas e serviços modernos, atraem também migrantes de qualificação diversa oriundos de outras regiões brasileiras.

Dessa forma, segundo Santos (1993), convivem nas cidades do agronegócio dois tipos de migrantes: os "descendentes", migrantes qualificados (agrônomos, engenheiros, consultores, produtores etc.), provenientes, sobretudo, das áreas mais ricas do país, que possuem condições de consumo e cuja infraestrutura urbana é feita para seu usufruto; e os "ascendentes", pessoas expulsas do campo e provenientes das regiões mais pobres do país, que são excluídas do consumo moderno e que se alojam, sobretudo, nas áreas periféricas da cidade, aumentando o número de desempregados, subempregados e trabalhadores informais.

As cidades do agronegócio passam assim a ser caracterizadas pelo movimento e pela desigualdade (FREDERICO, 2010). Fluxos de toda ordem perpassam seus territórios, desde aqueles promovidos e controlados pelas grandes empresas (mercadorias, dinheiro, informação e profissionais qualificados), até a imigração de trabalhadores não qualificados, atraídos pelos signos da modernidade. Ao receber e emitir fluxos, as cidades do agronegócio se configuram como um mosaico de interações. A divisão social, técnica e territorial do trabalho estabelecida nas cidades do campo reproduzem, num curto espaço de tempo e de maneira mais acentuada, as desigualdades inerentes aos grandes centros urbanos brasileiros (ELIAS, 2007).

\section{O mercado e o Estado: tradings agrícolas e uso corporativo do território}

O atual período da globalização (SANTOS, 2000), emergente na década de 1970, se caracteriza por importantes transformações de ordem técnica e política, que alteraram a relação entre o Estado e as grandes empresas mundiais. A planetarização das redes de circulação e comunicação (RAFFESTIN, 1993) e a hegemonia da política neoliberal (HARVEY, 2007) permitiram às grandes empresas estabelecer estratégias e estruturar suas atividades na escala do planeta, interpretando os territórios como um "recurso" a ser explorado (SANTOS; SILVEIRA, 2001).

No caso da formação socioespacial brasileira, a crise fiscal do Estado, nas décadas de 1980 e 1990, associada à adoção das prerrogativas normativas do Consenso de Washington (FIORI, 2001), provocaram mudanças na regulação da produção agrícola. ${ }^{9} \mathrm{O}$ papel proeminente do Estado foi paulatinamente sendo assumido pelas grandes empresas, sobretudo aquelas vinculadas ao comércio de grãos. Segundo Morgan (1980), o comércio mundial de grãos é controlado por um pequeno grupo de

9 O Estado brasileiro reduziu o percentual do crédito agrícola ofertado, extinguiu diversos institutos de regulação da agricultura (Instituto Brasileiro do Café, Instituto do Açúcar e Álcool), enfraqueceu a Política de Garantia de Preços Mínimos, praticamente acabou com os estoques regulatórios e permitiu a comercialização de títulos financeiros indexados em commodities agrícolas, criando um elo entre o agronegócio e o mercado financeiro. 
grandes empresas, denominadas tradings ou "Gigantes do Grão", presentes desde as regiões de produção stricto sensu até os principais centros de consumo.

A organização reticular das empresas, além de lhes garantir o monopólio mundial do comércio de grãos, possibilita também o estabelecimento de círculos de cooperação com firmas de ramos complementares (logística, sementes, agrotóxicos e maquinário) e com os Estados. Além da liberalização normativa, que permitiu as privatizações e a ação desimpedida das grandes empresas, o Estado também coopera ao implantar no território formas (fixos) para viabilizar a fluidez corporativa. Para Santos (1996, p. 244), esse é o motivo pelo qual os territórios nacionais se transformam "num espaço nacional da economia internacional e os sistemas de engenharia difundidos pelo território são mais bem utilizados pelas empresas do que pela sociedade local".

$\mathrm{Na}$ fronteira agrícola moderna, as grandes empresas (tradings, agroindústrias, sementes e agrotóxicos) utilizam-se de diversas estratégias para regular e controlar os circuitos produtivos agrícolas, como: o fornecimento de crédito e de insumos químicos, biológicos e mecânicos; o controle da logística de circulação dos grãos; e o monopólio do processamento agroindustrial.

A grande participação das empresas privadas (tradings, sementes e agrotóxicos) no fornecimento do crédito de custeio ${ }^{10}$ acarreta no aumento do custo do dinheiro (maiores juros), na maior dependência dos produtores (comprometimento antecipado da safra) e na falta de garantia da

10 No estado do Mato Grosso, na safra de soja 2007-2008, as empresas privadas forneceram $75 \%$ do crédito de custeio. disponibilidade do crédito, sobretudo, nos momentos de crise da economia mundial. ${ }^{11}$

A logística é outro ramo importante de atuação das tradings. A crescente distância entre as novas áreas produtoras e os principais portos exportadores e a deficiência e a precariedade das infraestruturas de armazenamento e transporte existentes tornaram o controle da logística uma das principais formas de regulação da produção. Os sistemas de transporte dos grãos são controlados diretamente pelas tradings ou utilizados em parcerias com as empresas concessionárias.

No primeiro caso, o Grupo Amaggi e a Cargill controlam, respectivamente, a Hidrovia do Rio Madeira (com os portos de Porto Velho/RO e Itacoatiara/AM) e o porto de Santarém/PA (no rio Amazonas), que facilitam o escoamento dos grãos produzidos no oeste do Mato Grosso e no estado de Rondônia.

No caso das parcerias, o Terminal de Granéis do Guarujá (TGG), construído pelas empresas Maggi, Bunge e América Latina Logística (ALL), pode ser considerado um exemplo de cooperação entre tradings e empresas concessionárias. Localizado no Porto de Santos, o TGG consiste no maior armazém de recepção, armazenamento e embarque de granéis sólidos agrícolas da América Latina. O TGG conecta-se à malha ferroviária paulista e a Ferronorte, expedindo os grãos provenientes da região Centro-Oeste.

\footnotetext{
11 Na safra 2008-2009, as empresas privadas reduziram o montante de crédito ofertado aos produtores devido à crise econômica mundial, acarretando numa série de problemas para o custeio do plantio da safra.
} 
A ALL também possui parcerias com as tradings Cargill e ADM para o uso da ferrovia Ferronorte, principal artéria de exportação de grãos da fronteira agrícola. A empresa Vale, concessionária das ferrovias do Carajás e Norte-Sul, também possui parcerias com as tradings, com o objetivo de escoar, pelo Porto de Itaqui/MA, os grãos produzidos nos estados do Maranhão, Piauí, Tocantins e Pará.

Além dos sistemas de movimento (CONTEL, 2001) existentes, novas infraestruturas têm sido planejadas e construídas pelo Estado e concedidas às grandes empresas privadas, como: a extensão da ferrovia Ferronorte até a cidade de Rondonópolis/MT e da Norte-Sul até o estado de Goiás; a reforma e ampliação da ferrovia Nova Transnordestina e as futuras ferrovias Oeste-Leste (FIOL) e Centro-Oeste (FICO). As duas últimas, apesar de serem denominadas de ferrovias de "integração", na verdade comportam-se como "redes extravertidas" (SANTOS; SILVEIRA, 2001), pois têm como único objetivo conectar regiões produtoras de grãos (Oeste da Bahia, Tocantins e Mato Grosso) aos portos exportadores.

Outra política estratégica adotada pelas tradings é o controle do sistema de armazenamento de grãos. Este é essencial para o beneficiamento (limpeza, tratamento fitossanitário e conservação da massa) e cadenciamento da expedição dos grãos, evitando a sobrecarga dos sistemas de transporte e as oscilações no preço do frete.

Com as privatizações, o aumento da produção de grãos e a expansão da fronteira agrícola, os armazéns estatais predominantes até a década de 1980 tornaram-se insuficientes, obsoletos e mal localizados. As grandes empresas, desde então, se transformaram nos principais armazenadores, sobretudo, na fronteira agrícola moderna. A falta de silos estatais e nas fazendas torna os produtores dependentes das tradings. Eles são obrigados a utilizar as infraestruturas delas, vendendo os grãos antecipadamente ou na época da safra (preços menores e fretes maiores), submetendo-se a práticas duvidosas, ${ }^{12}$ sob o risco de não conseguir escoar a produção e acabar por perder (estragar) os grãos.

\section{Considerações finais}

O "imperativo das exportações" (SANTOS, 1999), resultado da combinação de uma política neoliberal hegemônica com o domínio da lógica financeira na esfera pública e privada, tem estimulado o aumento das exportações de commodities agrícolas, através da difusão da agricultura científica globalizada e da consequente especialização regional produtiva.

Em nenhuma outra região brasileira, a submissão à lógica das commodities e o consequente aprofundamento da especialização produtiva é tão expressivo quanto na fronteira agrícola moderna. A necessidade de exportar a qualquer custo, dentro da lógica das "vantagens comparativas", tem reforçado o "sentido da colonização" brasileira (PRADO JR., 1967), ao estimular a produção e a exportação de commodities agrícolas.

\footnotetext{
12 Segundo os produtores, as tradings utilizam-se de práticas ilícitas na pesagem e na classificação dos grãos. Para eles, as empresas armazenadoras alegam ter um percentual maior de grãos "ardidos" e "esverdeados" (considerados fora do padrão) e de umidade e impurezas do que existe realmente, descontando do montante final a ser pago pelos grãos.
} 
O "ideário da competitividade" (GORZ, 2004; CASTILLO, 2008), pautado no aumento incessante da eficiência produtiva (maior produtividade, menores custos e melhor qualidade) induz à especialização produtiva dos lugares, colocando regiões, muitas vezes localizadas em países diferentes, numa verdadeira relação de competição e dependência (FREDERICO, 2010).

Dentro da lógica da competitividade, apenas os agentes com maior acesso ao capital e à informação conseguem sobreviver, aumentando, dessa maneira, as desigualdades sociais e territoriais. A lógica interna se transforma e o território é reorganizado com o intuito de torná-lo funcional à produção moderna, como no caso das "regiões competitivas agrícolas" e das "cidades do agronegócio".

O privilégio conferido pelos investimentos público e privado a algumas regiões e atividades econômicas acaba por aprofundar a exclusão e o abandono de parcela significativa da população e do território brasileiro. Localmente, o atual modelo de modernização agrícola acaba por fragmentar e alienar o território (ISNARD, 1981), pois a sua lógica de funcionamento atende principalmente aos anseios "externos" das grandes empresas exportadoras, investidores financeiros e grandes produtores, em detrimento dos excluídos do campo, dos migrantes e das pequenas agroindústrias.

Na escala da formação socioespacial, a concentração dos investimentos em determinadas regiões produtivas acaba por desintegrar o território, exacerbando as desigualdades entre os "espaços luminosos" e os "espaços opacos" (SANTOS; SILVEIRA,
2001), isto é, entre as áreas de grande densidade técnica e informacional e os lugares desprovidos dos sistemas técnicos atuais.

O Estado, ao investir em grandes projetos territoriais (sistemas de irrigação, transposição fluvial, ferrovias, portos, hidrelétricas, silos) deve considerar a multiplicidade de usos que os sistemas de engenharia podem oferecer à população local. Lógica que difere dos atuais projetos criados para viabilizar a fluidez das commodities agrícolas, de caráter imediatista, vinculados ao interesse das grandes empresas, e monofuncionais, pois restritos a um único tipo de produto.

Ao invés de regiões competitivas, onde prevalece a "ordem global", "que busca impor uma única racionalidade" (SANTOS, 1996, p. 272), o Estado deve primar pela constituição de regiões cooperativas, que privilegiem a "ordem local", isto é, a lógica interna, do cotidiano compartilhado por todos os homens, empresas, instituições e formas de produção. As regiões cooperativas, além de apreender o controle técnico dos sistemas produtivos, também devem deter o controle político sobre o que produzir e como produzir.

A ideia é contrapor ao nexo da competitividade a lógica de um cotidiano mais solidário. Regiões cooperativas que valorizem a sua diversidade econômica, cultural e geográfica e que promovam uma maior complementaridade produtiva regional (ARAÚJO, 2000) e o consequente fortalecimento do mercado interno brasileiro. Um espaço articulado em rede com outros espaços, mas que se oponha à racionalidade única da ordem global e que privilegie a ordem soberana daqueles que vivem nos lugares. 


\section{Referências bibliográficas}

ARAÚJO, T. B. Dinâmica regional brasileira nos anos noventa: rumo à desintegração competitiva. In: CASTRO, I. E. et al. (Orgs.). Redescobrindo o Brasil: 500 anos depois. Rio de Janeiro: Bertrand Brasil, 2000. p. 73-89.

$A B$ 'SÁBER, A. Os domínios de natureza no Brasil: potencialidades paisagísticas. São Paulo: Ateliê, 2003.

BERNARDES, J. A. O novo tempo do capital no cerrado: a criação de novos territórios produtivos. In: BERNARDES, J. A.; ARACRI, L. A. S. (Orgs.). Espaço e circuitos produtivos: a cadeia carne/grãos no cerrado mato-grossense. Rio de Janeiro: Arquimedes, 2010, p. 15-27.

- Fronteiras da agricultura moderna no cerrado Norte/Nordeste: descontinuidades e permanências". In: BERNARDES, J. A.; BRANDÃO FILHO, J. B. (Orgs.). Geografias da soja II: a territorialidade do capital. Rio de Janeiro: Arquimedes/CNPq, 2009. p. 13-40.

CASTILLO, R. Agricultura globalizada e logística nos cerrados brasileiros. In: SILVEIRA, Márcio Rogério (Org.). Circulação, transportes e território: diferentes perspectivas. São Paulo: Expressão Popular, 2011. p. 331-354.

Sustentabilidade, globalização e desenvolvimento. In: OLIVEIRA, M. P. et al. (Orgs.). O Brasil, a América Latina e o mundo: espacialidades contemporâneas. Rio de Janeiro: Anpege/Clacso/Faperj/Lamparina, 2008. p. $401-410$.

- Exportar alimentos é a saída para o Brasil? O caso do complexo soja. In: ALBUQUERQUE, E. S. (Org.). Que país é esse? Pensando o Brasil contemporâneo. São Paulo: Globo, 2005. p. 283-306.

; FREDERICO, S. Dinâmica regional e globalização: espaços competitivos agrícolas no território brasileiro. Mercator, ano 9, n. 18, 2010a, p. 17-26.
Espaço geográfico, produção e movimento: uma reflexão sobre o conceito de circuito espacial produtivo. Sociedade \& Natureza (UFU. Online), v. 22, 2010b, p. 461474. Disponível em: <http://www.seer.ufu.br/index.php/s ociedadenatureza/article/view/11336 >. Acesso em: 20 out. 2013.

CATAIA, M. A. Geração de cidades e efeito modernizante da atividade agrícola no Centro-Oeste brasileiro. In: $\mathbf{X}$

Encontro de Geógrafos da América Latina, 2005, São Paulo, SP. Por uma geografia latinoamericana. Do labirinto da solidão ao espaço da solidariedade, 2005, p. 3297-3314.

CONTEL, F. B. Os sistemas de movimento do território brasileiro. In: SANTOS, M.; SILVEIRA, M. L. (Orgs.). Brasil: território e sociedade na aurora do século XXI. São Paulo: Record, 2001. p. 357-374.

DELGADO, G. C. Capital financeiro e agricultura no Brasil: 1965-1985. São Paulo: Icone, 1985.

DINIZ, Bernardo P. Campolina. O grande Cerrado do Brasil Central: geopolítica e economia. Tese (Doutorado em Geografia) Faculdade de Filosofia Letras e Ciências Humanas, Universidade de São Paulo, 2006.

ELIAS, Denise S. Agricultura e produção de espaços urbanos não metropolitanos: notas teórico-metodológicas. In: SPOSITO, M. E. B. (Org.). Cidades médias: espaços em transição. São Paulo: Expressão Popular, 2007. p. 113-137. (Coleção Geografia em Movimento.)

FIORI, J. L. 60 lições dos 90: uma década de neoliberalismo. São Paulo: Record, 2001.

FREDERICO, S. O novo tempo do cerrado: expansão dos fronts agrícolas e controle do sistema de armazenamento de grãos. São Paulo: Annablume, 2010. 
GORZ, A. Misérias do presente, riquezas do possível. São Paulo: Annablume, 2004.

HARVEY, D. A Brief History of Neoliberalism. New York: Oxford University Press, 2007.

O novo imperialismo. São Paulo: Loyola, 2004.

HUERTAS, D. M. Da fachada atlântica à imensidão amazônica: fronteira agrícola e integração territorial. São Paulo: Annablume, 2009.

ISNARD, H. O espaço geográfico. Coimbra, Portugal: Livraria Almeida, 1982.

KAGEYAMA, A. et al. O novo padrão agrícola brasileiro: do complexo rural aos complexos agroindustriais. In: DELGADO, G.; GASQUES, J. G.; VILLA VERDE, C. (Coords.). Agricultura e políticas públicas. Brasília: Ipea, 1990.

PORTO-GONÇALVES, C. W. A globalização da natureza e a natureza da globalização. Rio de Janeiro: Record, 2006.

PRADO JR., C. História econômica do Brasil. São Paulo: Brasiliense, 1967.

\section{MAZZALI, L. O processo recente de} reorganização agroindustrial: do complexo à organização "em rede". São Paulo: Editora UNESP, 2000.

MORAES, A. C. R. Bases da formação territorial do Brasil: o território colonial brasileiro no "longo" século XVI. São Paulo: Hucitec, 2000.

MORGAN, D. Les geants du grain. Fayard: Paris, 1980.

MÜLLER, G. Complexo agroindustrial e modernização agrária. São Paulo: Hucitec, 1989.

RAFFESTIN, C. Por uma geografia do poder. São Paulo: Ática, 1993.

REINERT, E. S. La globalización de la pobreza: cómo se enriquecieron los países ricos... y por qué los países pobres siguen siendo pobres. Barcelona: Crítica, 2007.

SANTOS, M. Por uma outra globalização: do pensamento único à consciência universal. Rio de Janeiro: Record, 2000.

- Guerra dos lugares. Folha de S.Paulo, Caderno Mais, 8 ago. 1999.

A natureza do espaço: técnica e tempo, razão e emoção. São Paulo: Hucitec, 1996.

. A urbanização brasileira. São Paulo: Hucitec, 1993.

. Circuitos espaciais da produção: um comentário. In: SOUZA, M. A. A.; SANTOS, M. (Orgs.). A construção do espaço. São Paulo: Nobel, 1986, p. 121-132.

. Espaço e método. São Paulo: Nobel, 1985.88 p.

- Sociedade e espaço: a formação social como categoria e como método. Boletim Paulista de Geografia, São Paulo, n. 54, 1977, p. 81-100.

; SILVEIRA, M. L. O Brasil: território e sociedade no início do século XXI. Rio de Janeiro: Record, 2001.

SILVA, J. G. A modernização dolorosa: estrutura agrária, fronteira agrícola e trabalhadores rurais no Brasil. Rio de Janeiro: Zahar, 1982.

O que é questão agrária. São Paulo: Brasiliense. 1980. (Coleção Primeiros Passos.)

SILVEIRA, M. L. Por um conteúdo da reflexão epistemológica da geografia. In: SOUZA, A. J.; SOUZA, E. B. C.; MAGNONI JÚNIOR, L. (Orgs.). Paisagem território região: em busca da identidade. Cascavel/PR: Edunioeste, 2000. Cap. 1, p. 21-28.

SORJ, B. Estado e classes sociais na agricultura brasileira. Rio de Janeiro: Zahar, 1980.

VENCOVSKY, V. P. Ferrovia e logística do agronegócio globalizado: uma avaliação das políticas públicas e privadas do sistema ferroviário brasileiro. Tese (Doutorado em Geografia) - Instituto de Geociências, Universidade Estadual de Campinas, 2011. 